\title{
Erratum to: Automatic Detection of Erythemato-Squamous Diseases Using k-Means Clustering
}

\author{
Elif Derya Übeyli • Erdoğan Doğdu
}

Published online: 3 June 2010

(C) Springer Science+Business Media, LLC 2010

\section{Erratum to: J Med Sys \\ DOI 10.1007/s10916-008-9229-6 \\ Volume 34, No. 2, p. 179-184}

The original version of this article contained a mistake. Section 2 including the used dataset description is corrected as in the following.

\section{Differential diagnosis of erythemato-squamous diseases}

Güvenir et al. [1] studied the classification of erythematosquamous diseases (psoriasis, seboreic dermatitis, lichen planus, pityriasis rosea, chronic dermatitis and pityriasis rubra pilaris). In dermatology departments the erythematosquamous diseases are often seen. The symptoms of these diseases are the clinical features of erythema and scaling and there are slight variations among the symptoms. Therefore, the differential diagnosis of erythematosquamous diseases is a difficult problem. As it is mentioned in the paper of Güvenir et al. [1], the patients were first evaluated clinically with 12 features. The important features in differential diagnosis are the degree of erythema and scaling, the borders of lesions, the presence of itching and koebner phenomenon, the formation of papules, the oral mucosa, elbows, knees and the scalp involvement and family history. According to Güvenir et al. [1] a successful diagnosis can be done with these clinical features only for some patients, but a biopsy is generally required for a definite and precise diagnosis. In their study, skin samples were used for the evaluation of 22 histopathological features. They noted that there is an obstacle for differential diagnosis due to the fact that a disease may have the histopathological features of another disease initially and may have the characteristic features further. For this reason, some samples represent the typical histopathological features of the disease, even though some of them do not. In this section, only a short description of diseases is presented and the readers should consult reference [1] for further details. In this study, we used the same dataset to apply the k-means classification method.

The online version of the original article can be found at http://dx.doi. org/10.1007/s10916-008-9229-6.

E. D. Übeyli $(\bowtie) \cdot$ E. Doğdu

Department of Electrical and Electronics Engineering,

Faculty of Engineering, TOBB Ekonomi ve Teknoloji Üniversitesi, 06530 Söğütözü, Ankara, Turkey

e-mail: edubeyli@etu.edu.tr

E. Doğdu

e-mail: edogdu@etu.edu.tr 